\title{
Formação e interdisciplinaridade entre docentes e egressos dos programas de pós-graduação stricto sensu da área de ciências ambientais no Brasil
}

O presente trabalho analisa os perfis das formações de docentes e egressos de programas de pós-graduação stricto sensu da grande área de Ciências Ambientais no Brasil, bem como apresenta um panorama das instituições, cursos oferecidos e distribuição por regiões brasileiras, tendo como referência os anos de 2011 e 2019 . A partir de reflexões teóricas sobre a interdisciplinaridade, busca-se compreender como a mesma pode ser construída nos programas da referida área de conhecimento, em função do percurso formativo dos docentes e de seus orientandos (egressos). A abordagem metodológica utilizada neste trabalho caracteriza-se por uma pesquisa documental, exploratória e descritiva, com abordagens quantitativa e qualitativa, por meio da qual se buscou conhecer o perfil acadêmico dos professores permanentes e colaboradores, bem como dos egressos dos cursos acadêmicos e profissionais (mestrado e doutorado) em Ciências Ambientais. Os resultados obtidos quanto aos docentes demostraram uma predominância, no nível de graduação, do curso de Ciências Biológicas, que se repetiu em todas as regiões, e uma trajetória disciplinar nos três níveis formativos (graduação, mestrado e doutorado). Quanto aos egressos, a graduação predominante também foi o curso de Ciências Biológicas, embora com maior diversidade de formaçães em nível de graduação, e uma relação interdisciplinar mais evidente quando relacionada com a formação de seus orientadores. Percebe-se uma mudança de perfil entre docentes e egressos, o que indica uma tendência ao desenvolvimento do diálogo e a superação gradual de barreiras entre as disciplinas, sendo favorável à prática da interdisciplinaridade.

Palavras-chave: Interdisciplinaridade; Ciências Ambientais; Formação; Docentes; Egressos.

\section{Formation and interdisciplinarity between teachers and graduates from the stricto sensu postgraduate programs in the environmental science area in Brazil}

The present work analyzes the profiles of the formation of teachers and graduates of stricto sensu graduate programs in the large area of Environmental Sciences in Brazil, as well as presenting an overview of the institutions, courses offered and distribution by Brazilian regions, having as reference the years from 2011 and 2019 . Based on theoretical reflections on interdisciplinarity, we seek to understand how it can be built in the programs of that area of knowledge, depending on the training path of teachers and their supervisors (graduates). The methodological approach used in this work is characterized by documentary, exploratory and descriptive research, with quantitative and qualitative approaches, through which it was sought to know the academic profile of permanent professors and collaborators, as well as those graduating from academic and professional courses. (master's and doctorate) in Environmental Sciences. The results obtained regarding the professors showed a predominance, at the undergraduate level, of the Biological Sciences course, which was repeated in al regions, and a disciplinary trajectory at the three training levels (undergraduate, master's and doctorate). As for graduates, the predominant degree was also the Biological Sciences course, although with a greater diversity of formations at the undergaduate level, and a more evident interdisciplinary relationship when related to the training of their supervisors. There is a change in the profile between professors and alumni, which indicates a tendency towards the development of dialogue and the gradual overcoming of barriers between disciplines, being favorable to the practice of interdisciplinarity.

Keywords: Interdisciplinarity; Environmental Sciences; Formation; Teachers; Graduates.

Topic: Ensino Superior, Pesquisa e Extensão

Reviewed anonymously in the process of blind peer.
Received: $\mathbf{2 8 / 0 4 / 2 0 2 1}$

Approved: 29/05/2021
Heloísa Rodrigues Nascimento (iD)

Universidade Federal do Tocantins, Brasil

http://lattes.cnpq.br/3686185433364679

http://orcid.org/0000-0002-1478-5000

heloisa@ifto.edu.br

Izabella Downar Bakalarczyk

Universidade Federal do Tocantins, Brasil

http://lattes.cnpq.br/5507949269274247

http://orcid.org/0000-0002-8454-9206

izabella.downar@gmail.com

Ludmila Normanha Benedetti Furtado (iD) Universidade Federal do Tocantins, Brasil http://lattes.cnpq.br/0845834083157147

http://orcid.org/0000-0002-4055-9242

ludmilabenedetti@gmail.com

c

DOI: 10.6008/CBPC2179-6858.2021.005.0058

\begin{abstract}
Tiago Costa Rodrigues (it)
Universidade Federal do Tocantins, Brasil

http://lattes.cnpq.br/9935306380104247

http://orcid.org/0000-0002-1906-8297

costa.rodrigues@mail.uft.edu.br

Elisandra Scapin (iD

Universidade Federal do Tocantins, Brasil

http://lattes.cnpq.br/9765872633375212

http://orcid.org/0000-0001-7506-308X

elisandrascapin2015@gmail.com

Lucas Barbosa e Souza (it)

Universidade Federal do Tocantins, Brasi http://lattes.cnpq.br/8310303536103062

http://orcid.org/0000-0001-7957-088X

lbsgeo@uft.edu.br
\end{abstract}

\section{Referencing this:}

NASCIMENTO, H. R.; BAKALARCZYK, I. D.; FURTADO, L. N. B.; RODRIGUES, T. C.; SCAPIN, E.; SOUZA, L. B.. Formação e interdisciplinaridade entre docentes e egressos dos programas de pósgraduação stricto sensu da área de ciências ambientais no Brasil. Revista Ibero Americana de Ciências Ambientais, v.12, n.5, p.744760, 2021. DOI: http://doi.org/10.6008/CBPC2179$\underline{6858.2021 .005 .0058}$ 


\section{INTRODUÇÃO}

A conturbada relação entre sociedade e natureza no mundo contemporâneo ocasionou o surgimento de diversos movimentos internacionais desde a segunda metade do século XX. De forma gradual, esses movimentos trouxeram para a discussão o desenvolvimento sustentável e a busca das soluções para os problemas socioambientais. A observação desse cenário de crise tem sugerido a ampliação do olhar a partir de múltiplas apreciações do conhecimento, que integrados, podem alcançar uma visão sistêmica ou de conjunto, visando à melhor compreensão dos seus efeitos e modos de enfrentamento (PHILLIPI JUNIOR et al., 2013).

Os temas ambientais, por sua gênese social, necessitam da colaboração dos diversos campos do saber para que sejam problematizados em sua complexidade (ASSIS, 2000). De acordo com Bowler (1992) e Assis (2000), o próprio surgimento das ciências ambientais como área do conhecimento acontece sob circunstâncias em que as temáticas relacionadas ao ambiente passam a ser entendidas como um problema pela sociedade, cabendo à ciência compreender o funcionamento e encontrar soluções para os diferentes problemas nesse campo.

O ideal de uma abordagem integradora sobre a natureza e a humanidade encontra suas raízes em tempos pré-científicos, quando filosofia e ciência formavam um campo unificado e de contornos indistinguíveis, até a compartimentação moderna das ciências e a revolução universitária do século XIX (BARRETO et al., 2007; LEFF, 2002). A divisão do conhecimento, conforme conhecemos, remete à concepção kantiana de ciências dedutivas e ciências empíricas, culminando com o paradigma positivista no século XIX, com a matematização dos campos do saber e com o empirismo lógico no século XX. O utilitarismo científico e o fracionamento da ciência refletem, assim, um dado momento histórico, inclusive em conjunção com a exploração da natureza sob o modo capitalista de produção.

Posteriormente, a partir da segunda metade do século XX, a integração e o holismo ganharam novo impulso, evoluindo de um caráter enciclopédico (somatório de conhecimentos, com baixa inter-relação), a tentativas fundamentadas na teoria geral dos sistemas (TGS) e no pensamento complexo, além de outras propostas. Essas novas tendências, por sua vez, encontram-se emolduradas por um contexto de crise ambiental e civilizatória, muito embora os interesses utilitaristas de produtividade, de mercado e os discursos atrelados ainda persistam (PETRAGLIA, 1995; MORIN, 2000; LEFF, 2002).

Os estudos que buscam o entendimento das relações humanas entre si e com o meio ambiente, precisam de uma abordagem interdisciplinar. Para tanto, é importante superar as dicotomias e convergir os campos de estudo, visando a uma integração pela abordagem holística, considerando a problemática ambiental a partir dos liames entre sociedade e natureza. Esse enfoque difere de outras teorias de cunho iluminista, cartesiano, positivista e pragmatista, que mantiveram a separação entre natureza e sociedade, embora tenham fornecido modelos sofisticados de como a natureza e a sociedade funcionam (PHILLIPI JUNIOR et al., 2013).

Os problemas ambientais apresentam-se como temas complexos que envolvem aspectos sociais e naturais, de manifestação espaço-temporal. Portanto, trata-se de um campo de pesquisa que exige a 
integração entre as diversas disciplinas existentes, tanto da área de ciências sociais, das ciências exatas e agrárias, quanto da área biológica e tecnológica. Assim, é possível utilizar as metodologias já desenvolvidas em cada campo, alcançando resultados na pesquisa ambiental, implicando enfoque totalizante e sistêmico, resultando em novos avanços para essas mesmas disciplinas (PHILIPPI JUNIOR et al., 2013).

Todavia, as abordagens ancoradas na ideia de integração e de interdisciplinaridade, motivadas pelas circunstâncias desafiadoras de multiescalaridade e de complexidade da problemática ambiental, têm lugar no espaço cientificamente compartimentado da universidade, em seu modelo convencional de institutos, departamentos e cursos disciplinares (LEFF, 2001). Assim, as ciências ambientais, como campo interdisciplinar, surgem numa envoltória e legado que pouco colaboram, valorizam e oportunizam o exercício da interdisciplinaridade.

Para Cesco (2011), “É claro que o recorte disciplinar deu nascimento a territórios de poder, territórios de identificação, que fazem com que seja difícil ultrapassar as barreiras e promover a colaboração". Assim, um considerável desafio intelectual acaba por se fazer presente, especialmente quando "trata-se de fazer colaborar disciplinas que não vão enxergar os mesmos níveis de realidade. Em particular, fazer colaborar disciplinas que trabalham questões concretas, práticas e materiais da realidade com outras que trabalham com dimensões não tão palpáveis, imateriais, conceituais" (CESCO, 2011).

Não é possível adentrar os meandros da questão formativa no campo interdisciplinar, com seus desafios, limitações e estratégias, senão pela consideração das formações disciplinares, a priori, como ponto de partida para a transformação. Zabalza (2004) assevera que os conteúdos formativos devem oportunizar novas possibilidades de desenvolvimento pessoal, conhecimentos e habilidades, valores e atitudes, e enriquecimento das experiências. Uma vez que as formações disciplinares estão postas, a conseguinte formação interdisciplinar não cairá num terreno vazio, nem substituirá a formação anterior. Nesse aspecto, a diversidade formativa poderá operar com melhor desenvoltura do campo disciplinar para o campo interdisciplinar e vice-versa. Transita, assim, de um modo construtivo, entre duas formas não necessariamente excludentes de se fazer ciência e de se agir cientificamente.

Para Leff (2001), a interdisciplinaridade é a prática intersubjetiva, sendo que cada sujeito é também um sujeito da ciência e do conhecimento. Sendo assim, o encontro de sujeitos com diferentes conhecimentos irá oportunizá-la. Não garantir, mas criar condições para tal, por meio de um "[...] processo de intercâmbio teórico, metodológico, conceitual e terminológico" (LEFF, 2002). Para isso, o diálogo é fundamental. O contato profundo com o outro, com o diferente, para possibilitar transferências, ressignificações e uma fusão dos saberes para além de um nível retórico. Nesse caso, a variedade de formações se torna exclusivamente um ponto de partida, no qual transcorrem exercícios diante de situações concretas em que a cooperação, as trocas e a busca por soluções se façam no coletivo. Leff complementa fazendo uma analogia: "[...] a função dos sujeitos é análoga à função ecológica dos insetos que, ao coadjuvar no processo de polinização, fertilizam os códigos genéticos inscritos nas populações botânicas e mobilizam a evolução do ecossistema produtivo de conhecimento inscrito nas estruturas conceituais das teorias científicas" (LEFF, 2002). 
Para Coimbra (2000), a palavra interdisciplinaridade traz o “[...] vínculo não apenas entre saberes, mas principalmente, de um saber com outro saber, ou dos saberes entre si, numa sorte de complementaridade, de cooperação solidária, em função da realidade conhecida ou estudada". E ainda

Consiste num tema, objeto ou abordagem em que duas ou mais disciplinas, intencionalmente estabelecem interações e vínculos entre si, para alcançar um conhecimento mais abrangente, ao mesmo tempo diversificado e unificado. Cada disciplina, ciência ou técnica mantém a sua própria identidade, conserva sua metodologia e observa os limites dos seus respectivos campos. (COIMBRA, 2000)

A compreensão do conceito de interdisciplinaridade perpassa o entendimento do conceito de disciplina também porque "a perspectiva interdisciplinar se alimenta da perspectiva disciplinar, não sendo contrária a ela" (SATOLO et al., 2019). Mas para Morin (2000), "os avanços disciplinares das ciências não trouxeram apenas as vantagens da divisão do trabalho, trouxeram também os inconvenientes da hiperespecialização, do parcelamento e da fragmentação do saber". Por isso, o conhecimento disciplinar se mostra limitado quando os problemas a serem resolvidos envolvem questões complexas, como a sociedade e sua relação com a natureza. A redução da complexidade impede a solução de problemas nesse campo. (BAUMGARTEN et al., 2007). Surge, então, a necessidade interdisciplinar, que segundo Jantsch et al. (1995), se deu a partir de demandas sociais enraizadas num determinado período histórico e não por uma iniciativa isolada, destituída de historicidade.

Conforme Satolo et al. (2019), apoiados em Lenoir et al. (2004), há três principais conceitos de interdisciplinaridade considerados verdadeiros movimentos impulsionadores desta. 0 primeiro, associado à corrente científica francesa, "se baseia em dimensões epistemológicas dos saberes disciplinares e na racionalidade científica" é considerado lógico racional e é centrado na busca de significado; o segundo, associado à corrente científica norte-americana, é metodológico e tem uma forte preocupação com a lógica instrumental em busca da funcionalidade social; e o terceiro e último, associado à corrente científica brasileira emergente, "privilegia as dimensões humanas e afetivas, expressando uma lógica subjetiva dirigida à procura do próprio ser" (SATOLO et al., 2019).

No Brasil, o conceito de interdisciplinaridade possui duas vertentes teóricas mais expressivas, a primeira justamente centrada na filosofia do sujeito, evidenciando a autonomia das ideias ou do sujeito pensante sobre os objetos, com sua origem nas pesquisas de Hilton Japiassu e Ivani Fazenda, e a segunda vertente histórico-crítica, de abordagem marxista (SATOLO, 2019). Na perspectiva de Hilton Japiassu, a interdisciplinaridade foge do conceito apenas teórico, e se firma como uma prática. O objeto de estudo é que vai gerar a necessidade científica da interdisciplinaridade e a característica central desta consiste no fato de incorporar os resultados de várias disciplinas, "tomando-lhes de empréstimo esquemas conceituais de análise a fim de fazê-los integrar, depois de havê-los comparado e julgado" (SATOLO et al., 2019).

O meio ambiente, enquanto campo de pesquisa necessita de uma revisão sobre a fragmentação do conhecimento e da mudança do modelo disciplinar, buscando assim obter uma visão geral a respeito de determinado problema ambiental, implicando na reorganização das disciplinas, transformação de conceitos e abertura de novos campos de aplicação (PHILIPPI et al., 2013; LEFF, 2001). A prática interdisciplinar busca a produção de conhecimentos, diálogos entre saberes, colaboração entre diferentes áreas específicas, 
propondo a organização interdisciplinar do conhecimento para o desenvolvimento sustentável. Refere-se à integração prática de diversos saberes no tratamento de um problema comum (LEFF, 2001).

Ainda, de acordo com Etges (1993), vêm-se princípios fundantes da interdisciplinaridade, que

[...] enquanto princípio mediador entre as diferentes disciplinas, não poderá jamais ser elemento de redução a um denominador comum, mas elemento teórico-metodológico da diferença e da criatividade. A interdisciplinaridade e o princípio da máxima exploração das potencialidades de cada ciência, da compreensão dos seus limites, mas, acima de tudo, e o princípio da diversidade e da criatividade.

A área de Ciências Ambientais tem como momento simbólico de criação na CAPES o ano de 2011, no Dia do Meio Ambiente, 5 de junho. A área foi criada em decorrência da experiência de Programas da Área Interdisciplinar, sobretudo da Câmara do Meio Ambiente e Ciências Agrárias, a partir da necessidade de abordar os desafios ambientais, considerando a interação entre sistemas antrópicos e naturais que emergem no mundo contemporâneo (CAPES, 2013; CAPES, 2016). O surgimento da temática, enquanto campo de pesquisa e área de conhecimento, constitui parte do processo de institucionalização da questão ambiental na própria sociedade como um todo (PHILIPPI JUNIOR et al., 2013).

A área das Ciências Ambientais contempla a abordagem interdisciplinar, que está intrínseca ao seu projeto de criação, com enfoque na construção do conhecimento a partir da problemática/complexidade ambiental que se deseja compreender e definir. Por isso, os programas de pós-graduação, ao serem vinculados a essa área, devem apresentar a diversidade, o diálogo e a interface com várias disciplinas no âmbito de suas áreas de concentração e linhas de pesquisa (CAPES, 2013).

Considerando essas premissas, o objetivo deste trabalho foi investigar o perfil acadêmico dos docentes e egressos dos programas de pós-graduação stricto sensu na área de Ciências Ambientais no Brasil, através de uma análise comparativa entre regiões, áreas de conhecimento e níveis de formação, tendo como referência os anos de 2011 e de 2019. O perfil acadêmico, nesse caso, foi compreendido como uma primeira possibilidade para o exercício interdisciplinar, em especial pela diversidade das formações. Logo, o trabalho buscou, através da estrutura e formação do corpo docente dos programas de pósgraduação e da formação dos seus egressos, a compreensão de como a interdisciplinaridade tem se apresentado na área de Ciências Ambientais. Reitera-se que não se intentou apontar e/ou classificar a interdisciplinaridade nos programas de pós-graduação, mas sistematizar elementos que indiquem o comportamento da proposta interdisciplinar na composição do corpo docente dos programas, além do reflexo na formação dos egressos.

Apesar da pesquisa não ter por finalidade a compreensão de embates no campo da subjetividade, os dados apresentados podem identificar as oportunidades para a construção de "diálogos" entre orientador e egresso. Assim, busca-se evidenciar o potencial de interdisciplinaridade proveniente do percurso formativo do docente e, certamente, outro que se forja nas trocas de experiências entre os sujeitos envolvidos, orientador e orientando que, com suas produções, constituem os programas em que estão inseridos.

\section{METODOLOGIA}

A abordagem metodológica empregada neste trabalho caracteriza-se por uma pesquisa 
documental, exploratória e descritiva, com abordagens quantitativa e qualitativa, por meio da qual se buscou conhecer o perfil acadêmico dos docentes permanentes e colaboradores, bem como de egressos, em cursos de pós-graduação stricto sensu (mestrado e doutorado nas modalidades acadêmica e profissional) na área de Ciências Ambientais no Brasil.

Na primeira etapa, foram levantados os programas de pós-graduação stricto sensu em atividade na área de Ciências Ambientais no país. Os dados foram coletados na Plataforma Sucupira, na aba dados e estatísticas, no menu dados abertos, gerados por meio de relatório, e têm como ano-base 2018 (referente ao ciclo 2017-2020), contendo informações relevantes como: nome do programa, área, nome do curso, nível do curso, ano de criação, nota de avaliação, região, conceito e município. Foram coletadas, na primeira etapa da pesquisa, o nome da instituição de ensino, o município, o nome do curso, o nível do curso (mestrado acadêmico/profissional e doutorado acadêmico/profissional), o ano de início e/ou abertura e o conceito de cada programa, para as cinco macrorregiões brasileiras.

Na segunda etapa, realizou-se o levantamento do corpo docente dos programas de pós-graduação, na página dos programas listados na primeira etapa. A seguir, foi feita a consulta ao currículo dos docentes na plataforma Lattes, no portal do Conselho Nacional de Desenvolvimento Científico e Tecnológico (CNPq), para caracterizar o perfil acadêmico destes. Nessa etapa foram obtidas as seguintes informações: nome do docente, graduação, mestrado, doutorado, pós-doutorado e o link do currículo Lattes. Os dados obtidos nos levantamentos foram tabulados em planilhas do software Microsoft Excel ${ }^{\circledR}$.

Ao analisar os dados relativos aos docentes, buscou-se identificar quais as formações em nível de graduação predominam em cada região e também as áreas do conhecimento, destacando as cinco primeiras, para posterior comparação regional. Analisou-se também o grau de 'linearidade' da formação destes, atribuindo valores de 1 a 3, sendo 1 para formação na mesma área do conhecimento nos três níveis de formação (graduação, mestrado e doutorado), 2 para duas formações na mesma área do conhecimento e 3 para três formações em áreas distintas do conhecimento, sendo que quanto maior o valor, mais variado o percurso formativo. Utilizou-se como referência a Tabela das Áreas de Conhecimento da CAPES, que define o Índice geral das grandes áreas e sub-áreas do conhecimento devido à variedade de nomenclaturas e de formações que apareceram na amostra. No caso dos docentes que apresentaram duas ou mais graduações, optou-se por considerar a que estava mais relacionada à área de atuação dos mesmos.

A terceira etapa consistiu em um levantamento sobre a formação dos egressos, realizado por amostragem, de acordo com dois critérios: o primeiro, meramente quantitativo, foi a seleção de $50 \%$ da quantidade total de programas de pós-graduação stricto sensu de cada região. E o segundo, cronológico, levou em conta o ano de criação do programa, de maneira que fossem selecionados os programas mais antigos e com mais tempo de funcionamento, ou seja, iniciados antes do ano de 2011. Dependendo da região, caso os programas anteriores a 2011 não fossem suficientes para atingir o quantitativo de 50\% (primeiro critério), programas iniciados após o ano de 2011 foram gradualmente incorporados à amostra.

Após a seleção dos programas que atendiam aos critérios citados, buscaram-se as informações nos repositórios de teses e dissertações dos referidos programas, e/ou diretamente pelo currículo Lattes do 
docente participante do programa, na aba orientações concluídas. Para essa coleta foram levantados os seguintes dados: nome do egresso, título das dissertações e teses defendidas para o ano de 2011 e de 2019, nome do orientador, e graduação. Os dados também foram organizados em planilhas do Microsoft Excel $^{\circledR}$.

Fez-se a consulta ao currículo Lattes dos egressos para levantar a informação sobre sua graduação, com o objetivo de analisá-la comparativamente com a graduação de seus orientadores. Para essa análise, utilizou-se o mesmo critério de valores da análise da formação docente, limitando-se, no entanto, a avaliar somente o nível de formação da graduação de ambos, sendo 1 (um) para ambas as formações na mesma área do conhecimento e 2 (dois) para formações em diferentes áreas do conhecimento.

Finalizada a etapa de levantamento de dados, para interpretá-los foram utilizadas ferramentas do Microsoft Excel ${ }^{\circledast}$ para quantificar as informações e elaborar gráficos e tabelas com os resultados obtidos. Por fim, os dados foram compreendidos à luz da perspectiva teórica que trata do tema da interdisciplinaridade na produção de conhecimento, seus desafios e possibilidades.

\section{RESULTADOS E DISCUSSÃO}

A CAPES criou a Coordenação de Área de Ciências Ambientais - CACiamb em decorrência da experiência acumulada pelos programas da área Interdisciplinar. A abordagem interdisciplinar é intrínseca à área de Ciências Ambientais, refletindo no desenvolvimento de pesquisas que buscam a construção de novas práticas e metodologias envolvendo as questões ambientais, diante da complexidade que envolve diversos atores e sua interação com o meio ambiente (CAPES, 2016).

A área de Ciências Ambientais iniciou suas atividades com 57 programas, distribuídos em 73 cursos no Brasil (CAPES, 2016) e, segundo os dados coletados, possui hoje 163 cursos em funcionamento, tendo apresentado um crescimento de 123,29\%. O quadro 1 apresenta a distribuição dos cursos de pósgraduação stricto sensu na área de Ciências Ambientais, por região do país.

Quadro 1: Distribuição de cursos de pós-graduação stricto sensu no Brasil por regiões

\begin{tabular}{|c|c|c|c|c|c|}
\hline Regiões & Norte & Nordeste & Centro-Oeste & Sudeste & Sul \\
\hline $\begin{array}{c}\text { № de cursos em } \\
\text { funcionamento (2020) }\end{array}$ & 20 & 29 & 29 & 51 & 34 \\
\hline $\begin{array}{c}\text { Ano de criação do 10 } \\
\text { programa }\end{array}$ & 2000 & 1995 & 1996 & 1990 & 1993 \\
\hline
\end{tabular}

Fonte: CAPES (2020)

\section{Região Sudeste}

A Região Sudeste do Brasil apresenta 53 cursos, 51 deles ainda em funcionamento, um (1) em situação de desativação (Mestrado em Ciência e Tecnologia Ambiental na Universidade do Sagrado Coração) e um (1) em situação de Projeto (Mestrado em Ciência e Tecnologia Ambiental na Universidade Santa Cecília). Esta região apresenta cursos de pós-graduação stricto sensu nas três modalidades, sendo eles: 23 mestrados acadêmicos, 14 mestrados profissionais, 15 doutorados acadêmicos e 1 doutorado profissional. Um total de doze programas apresenta os dois níveis de formação (mestrado e doutorado) e 
por essa razão possuem o corpo docente comum, resultando em 41 instituições/programas diferentes. A maior parte dos cursos dessa região apresenta conceito $4^{1}(53,85 \%)$, seguido pelo conceito $3(32,69 \%)$, conceito 7 (7,69\%) e conceito 6 (3,85\%). O primeiro curso de pós-graduação foi o de mestrado em Ciência Ambiental da Universidade de São Paulo (USP), iniciado no ano de 1990. O curso mais recente iniciou no ano de 2020, doutorado em Meio Ambiente e Recursos Hídricos na Universidade Federal de Itajubá.

\section{Região Sul}

A Região Sul do Brasil apresenta 34 programas em funcionamento², apresentando cursos de pósgraduação stricto sensu em três modalidades, sendo eles: 22 mestrados acadêmicos, 4 mestrados profissionais e 8 doutorados acadêmicos. É importante ressaltar que alguns programas, assim como na região Sudeste, por apresentarem os dois níveis de formação (mestrado e doutorado), possuem o corpo docente comum, resultando em 26 instituições/programas diferentes. A maioria dos cursos dessa região, apresenta conceito $3(40 \%)$, seguido pelos conceitos $4(33 \%)$ e $5(27 \%)$. Ao analisar a variável ano de início e/ou abertura dos cursos de pós-graduação, o primeiro curso aberto na área de Ciências Ambientais da Região Sul foi o mestrado em Meio Ambiente e Desenvolvimento, da Universidade Federal do Paraná (UFPR), iniciado no ano de 1993 e o mais recente é o mestrado em Ciência e Tecnologia Ambiental, da Universidade Federal de Santa Maria (UFSM), iniciado em 2018.

\section{Região Nordeste}

A região Nordeste do Brasil possui 29 programas em funcionamento, apresentando cursos de pósgraduação stricto sensu em três modalidades, sendo eles: 19 mestrados acadêmicos, 7 mestrados profissionais e 3 doutorados acadêmicos. Durante a realização da consulta nas páginas eletrônicas dos programas de pós-graduação, obteve-se a informação referente a 26 programas, pois 3 programas possuem mestrado e doutorado acadêmico e o corpo docente em comum, apesar dos anos de início serem diferentes. Ao analisar a variável ano de início e/ou abertura dos cursos de pós-graduação, o primeiro curso teve início no ano de 1995, o mestrado em Desenvolvimento e Meio Ambiente, na Universidade Federal de Sergipe. Os cursos mais recentes iniciaram no ano de 2017, totalizando a abertura de 3 cursos de mestrado, sendo eles: mestrado em Ciência e Tecnologia Ambiental para o Semiárido (UFPE), mestrado em Ciências e Tecnologia Ambiental (UFSBA) e o mestrado profissional em Tecnologias Ambientais (IFAL).

É importante salientar que na Região Nordeste existe o Programa de Pós-Graduação em Desenvolvimento e Meio Ambiente (PRODEMA), no formato de rede, que conta com a participação de sete universidades da região, sendo elas: Universidade do Piauí, Universidade Federal do Ceará, Universidade Federal do Rio Grande do Norte, Universidade Federal da Paraíba, Universidade Federal de Pernambuco, Universidade Federal de Sergipe e Universidade Estadual de Santa Cruz. Nessas instituições são ofertados

\footnotetext{
${ }^{1} \mathrm{~A}$ avaliação dos cursos de mestrado (acadêmico e profissional) e doutorado (acadêmico e profissional) no Brasil é realizada uma vez a cada quatro anos pela CAPES. Ela atribui notas que de 1 a 7. As notas 1 e 2 implicam o descredenciamento do curso. As notas 3 a 5 equivalem respectivamente a "regular", "bom" e "muito bom". Além disso, há também os conceitos 6 e 7, que expressam excelência constatada em nível internacional. Somente os programas que têm doutorado podem aspirar às notas 6 e 7 (CAPES, 2007).

${ }^{2}$ A tabela original da CAPES apresenta 36 programas listados, porém um deles encontra-se em projeto (Doutorado em Ciências Ambientais da UNICHAPECÓ) e o outro em desativação (Mestrado em Gerenciamento Costeiro da Universidade Federal do Rio Grande) e foram, portanto, retirados do quadro 1, que apresenta somente os programas em funcionamento. 
mestrados e doutorados acadêmicos na área das Ciências Ambientais.

\section{Região Centro Oeste}

A região Centro Oeste do Brasil possui dezenove 19 programas em funcionamento, apresentando cursos de pós-graduação stricto sensu em três modalidades, sendo eles: 17 mestrados acadêmicos, 2 mestrados profissionais e 10 doutorados acadêmicos. Durante a realização da consulta nas páginas eletrônicas dos programas de pós-graduação, obteve-se a informação referente a todos os 19 programas. Algumas pós-graduações apresentaram corpo docente comum, ou seja, o mesmo docente faz parte de mais de um programa. Nesse caso, para obter o número total de docentes foram excluídos os nomes em multiplicidade, contabilizando estes docentes a partir do programa mais antigo ao qual estão ligados. Ao analisar a variável ano de início ou abertura dos cursos de pós-graduação, o primeiro iniciou-se no ano de 1996, o mestrado em Desenvolvimento Sustentável da Universidade de Brasília. O curso mais recente data de 2017, sendo o programa em Gestão e Tecnologia Ambiental, da Universidade Federal do Mato Grosso.

\section{Região Norte}

A região Norte do Brasil tem 19 programas em funcionamento, o menor número entre as regiões brasileiras, e apresenta cursos de pós-graduação stricto sensu em três modalidades, sendo eles: 12 mestrados acadêmicos, 3 mestrados profissionais, 5 doutorados acadêmicos. Pela consulta nas páginas eletrônicas dos programas de pós-graduação obteve-se informações referentes apenas a 15 programas, pois nem todos têm suas informações apresentadas nos portais institucionais. Pelo menos três pósgraduações apresentaram corpo docente comum, ou seja, o mesmo docente faz parte de mais de um programa, tendo sido adotado o mesmo expediente já descrito, de retirada dos nomes em multiplicidade e manutenção somente no programa mais antigo de vínculo do docente. Sobre o ano de início e/ou abertura dos cursos de pós-graduação, o primeiro curso iniciou-se no ano de 2000, o mestrado em Ciências do Ambiente e Sustentabilidade na Amazônia, da Universidade Federal do Amazonas. Já os cursos mais recentes, iniciaram-se no ano de 2018 e 2019, totalizando a abertura de dois cursos de mestrado acadêmico, sendo eles: mestrado em Oceanografia da Universidade Federal do Pará (2018) e mestrado em Ciências Ambientais da Universidade Federal do Acre (2019).

\section{Análise comparativa dos docentes nas regiões brasileira}

Para apresentar a análise comparativa dos cursos de pós-graduação stricto sensu na área de Ciências Ambientais inicia-se pela apresentação da quantidade de cursos e modalidade por região, estes dados são apresentados na tabela 1.

A tabela 1 mostra certo equilíbrio em relação à quantidade de mestrados acadêmicos nas regiões brasileiras, porém essa quantidade é ligeiramente menor na região Norte. A quantidade de mestrados profissionais é maior na região Sudeste e a região Nordeste é a que possui a menor quantidade de cursos de doutorado acadêmico. Após a identificação dos programas por região, iniciou-se a pesquisa pelos 
docentes permanentes e colaboradores, integrantes destes. Em relação à quantidade referente aos docentes atuantes nesses programas, obtiveram-se os dados que podem ser observados na tabela 2.

Tabela 1: Distribuição das modalidades de cursos de pós-graduação stricto sensu na área de Ciências Ambientais por região no Brasil

\begin{tabular}{ccccc}
\hline Região & $\begin{array}{c}\text { Mestrado } \\
\text { acadêmico }\end{array}$ & $\begin{array}{c}\text { Doutorado } \\
\text { acadêmico }\end{array}$ & Mestrado Profissional & Doutorado Profissional \\
\hline Sudeste & 23 & 15 & 14 & 1 \\
Sul & 22 & 8 & 4 & - \\
Nordeste & 19 & 3 & 7 & - \\
Centro Oeste & 17 & 10 & 2 & - \\
Norte & 12 & 5 & 3 & - \\
\hline
\end{tabular}

Fonte: CAPES (2020).

Tabela 2: Quantidade de docentes dos cursos de pós-graduação stricto sensu na área de Ciências Ambientais por região no Brasil

\begin{tabular}{cc}
\hline Região & Quantidade de docentes \\
\hline Sudeste & 751 \\
Sul & 419 \\
Nordeste & 490 \\
Centro Oeste & 302 \\
Norte & 285 \\
\hline
\end{tabular}

Fonte: Páginas eletrônicas dos programas de pós-graduação (2020)

A partir dos dados da tabela 2, obteve-se na consulta ao currículo Lattes de cada docente a sua formação em nível de graduação, mestrado e doutorado. Quanto à sua formação em nível de graduação, foram identificadas várias formações, sendo que em números elas representam: 59 tipos de formação em nível de graduação na região Sudeste, 56 tipos de formação na região Sul, 60 tipos de formação na região Nordeste, 54 tipos de formação na região Centro Oeste e 44 tipos de formação na região Norte. No gráfico 1 , visualizam-se os cinco tipos de formações ${ }^{3}$ predominantes em cada região do país.

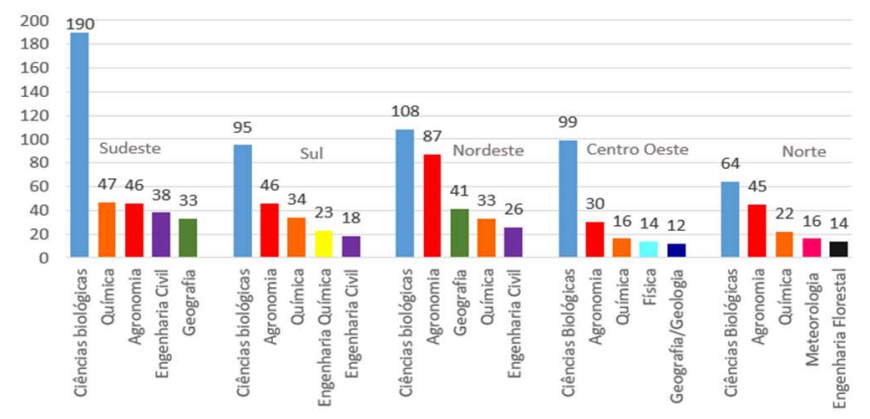

Gráfico 1: Cinco formações de graduação predominantes por região no Brasil.

Fonte: Plataforma Lattes/CNPq (2020).

Percebe-se pelos dados apresentados no gráfico 1 uma graduação predominante em primeiro lugar para todas as regiões: Ciências Biológicas. Para o segundo lugar, uma semelhança entre as regiões Sul, Nordeste, Centro Oeste e Norte, com a graduação em Agronomia. Porém, se analisarmos cada região em relação à diversidade das áreas de conhecimento quanto à formação em nível de graduação dos docentes, concentram-se as seguintes: Ciências Biológicas, Ciências Agrárias, Ciências Exatas e da Terra, Engenharias, variando a área de Ciências Humanas, que esteve presente nas regiões Sudeste, Nordeste e Centro Oeste.

Os cinco primeiros tipos de formação em nível de graduação na região Sudeste representam

\footnotetext{
${ }^{3}$ Não foi possível identificar a graduação de alguns docentes, seja pela falta dessa informação ou por não localizar esse currículo na Plataforma Lattes. 
$52,47 \%$ do total da amostra. Já na região Sul, esse percentual atinge $50 \%$, na região Nordeste $60 \%$, na região Centro Oeste, $60,6 \%$ e na região Norte, $56,5 \%$ dos docentes. Diante desses resultados, verifica-se que as formações em nível de graduação são bastante diversificadas nos percentuais restantes das regiões Sudeste, Sul, Nordeste, Centro Oeste e Norte, respectivamente equivalente a 47,53\%, 50\%, 40\%, 39,40\% e $43,50 \%$ das outras graduações identificadas na pesquisa. Com isso, pode-se concluir que, independentemente da região, há uma variedade muito grande de formações em nível de graduação dos docentes/orientadores, o que pode ser um fator favorável à prática da interdisciplinaridade nos programas.

Sobre as formações, Maranhão (2010) realizou uma pesquisa sobre a concentração temática desenvolvida nas pesquisas e a correlação desta com as áreas de conhecimento, sendo que: a área de Ciências Humanas e as Ciências Sociais Aplicadas concentraram-se em pesquisas sobre ambiente e desenvolvimento sustentável, enquanto as áreas de Ciências Biológicas, Agrárias e Exatas dedicaram-se principalmente aos temas envolvendo a biodiversidade e os recursos naturais. Esses resultados obtidos por Maranhão (2010) convergem com os resultados encontrados nesta pesquisa sobre aa áreas de conhecimento, pois observando as áreas de formação em nível de graduação dos docentes, é possível visualizar uma concentração das formações nas mesmas áreas citadas pela pesquisadora. De acordo com Maranhão (2010), é crescente o interesse para a realização de pesquisas sobre os temas ambiente, desenvolvimento sustentável, biodiversidade e recursos naturais para o desenvolvimento científico e tecnológico, ainda que as grandes áreas de conhecimento apresentem o enfoque direcionado nas pesquisas.

A área de Ciências Ambientais apresenta nos projetos de cursos de pós-graduação stricto sensu essa perspectiva de integração entre as diversas áreas do saber, cuja finalidade é a obtenção de conhecimento e a solução para os problemas ambientais. A possibilidade de interação entre a área de ciências naturais, ciências sociais, ciências humanas, ciências exatas, agrárias e engenharias possui enorme potencial. $\mathrm{O}$ foco da interdisciplinaridade, nesse contexto, é ultrapassar a barreira disciplinar e conectar as disciplinas e as áreas correlatas para resultar em novos conhecimentos, com benefícios à comunidade acadêmica e à sociedade.

Diante dos resultados apresentados pela pesquisa, evidencia-se a diversidade de formações em nível de graduação para os docentes, sendo estes atores principais na condução do processo de pesquisa interdisciplinar. Assim, a integração do conhecimento disciplinar, representado pela formação docente e discente nos programas, poderá conduzir às práticas interdisciplinares, gerando novos conceitos e métodos, ampliando a visão frente aos problemas ambientais enfrentados na atualidade. Fazenda (2003, p. 28) complementa esse raciocínio, explicando que a "interdisciplinaridade nos parece hoje mais processo do que produto", considerando que ainda estamos em processo de evolução, encontrando caminhos viáveis para consolidação dessa prática nas pesquisas. A pesquisa mostrou ainda um panorama sobre a quantidade de docentes que possui duas ou mais formações em nível de graduação por região, atuantes na pósgraduação, conforme demonstra a tabela 3 . 
Tabela 3: Quantidade de docentes que possuem duas ou mais graduações

\begin{tabular}{ccc}
\hline Região & Quantidade de docentes & (\%) do total de docentes por região \\
\hline Sudeste & 83 & $11,37 \%$ \\
Sul & 16 & $3,8 \%$ \\
Nordeste & 44 & $8,53 \%$ \\
Centro Oeste & 8 & $2,65 \%$ \\
Norte & 14 & $4,92 \%$ \\
\hline
\end{tabular}

Fonte: Plataforma Lattes/CNPq (2020).

Percebe-se que todas as regiões apresentam docentes com duas ou mais graduações, que nesses casos podem vir a contribuir com maior potencial para o desenvolvimento de trabalhos de dissertação ou tese de forma interdisciplinar, dada a própria experiência formativa. Quanto à experiência de pósdoutorado, a tabela 4 apresenta o percentual de docentes que a possuem e participam dos programas de pós-graduação stricto sensu em Ciências Ambientais, por região.

Tabela 4: Percentual de docentes com formação em nível de pós-doutorado

\begin{tabular}{ccc}
\hline Região & Possui Pós-doutorado & Não possui pós-doutorado \\
\hline Sudeste & $51 \%$ & $49 \%$ \\
Sul & $44 \%$ & $56 \%$ \\
Nordeste & $43 \%$ & $57 \%$ \\
Centro Oeste & $45 \%$ & $55 \%$ \\
Norte & $34 \%$ & $66 \%$ \\
\hline
\end{tabular}

Fonte: Plataforma Lattes/CNPq (2020).

Ao visualizar os dados da tabela 4, verifica-se que o maior percentual de docentes com formação de pós-doutorado está presente na região Sudeste. As regiões Sul, Nordeste e Centro Oeste possuem semelhança em números, em relação à quantidade de docentes com pós-doutorado. Já a região Norte possui a menor quantidade de docentes com essa formação, equivalente a $34 \%$ dos professores.

Considerando os dados levantados sobre a formação em nível de graduação, mestrado e doutorado dos docentes que participam dos programas de pós-graduação stricto sensu na área de Ciências Ambientais no Brasil, avaliou-se a linearidade das formações conforme os critérios explicados na seção metodológica. Os resultados dessa avaliação, por região, estão apresentados no gráfico 2.

Os resultados demonstram uma predominância na formação em nível de graduação, mestrado e doutorado na mesma área de conhecimento, sugerindo um perfil mais disciplinar. Porém, mesmo apresentando uma linearidade na mesma área de conhecimento, verifica-se a diversidade de formações entre os sujeitos, o que evidencia provável intercâmbio de conhecimento entre o docente e o discente. Com isso, pode-se ampliar a comunicação entre as áreas e caminhar rumo à construção de um saber de caráter interdisciplinar, envolvendo questões ambientais complexas e a busca por soluções viáveis para problemas ou incógnitas, aos quais os programas estão direcionados em suas linhas de pesquisa.

Em breve resumo das correntes de pensamento que influenciaram a fragmentação do conhecimento em forma de disciplinas, pode-se citar o paradigma cartesiano-newtoniano, responsável pela visão de mundo mecanicista. A revolução industrial também impulsionou a especialização do conhecimento, com finalidades produtivas. O positivismo contribuiu para a disseminação do modelo disciplinar e o enfoque nas especialidades. Hoje, essa visão compartimentada das disciplinas ainda está presente nas diversas áreas do saber, desde o nível escolar até a pós-graduação (COIMBRA, 2000). Porém, 
os conhecimentos adquiridos ao longo do tempo, por meio das disciplinas, não podem ser anulados, visto que contribuíram para os avanços e o desenvolvimento da ciência. A interdisciplinaridade surge com a finalidade de complementar as disciplinas, sendo que isso envolve a sua integração (SATOLO et al., 2019; PHILLIPI JUNIOR et al., 2000).

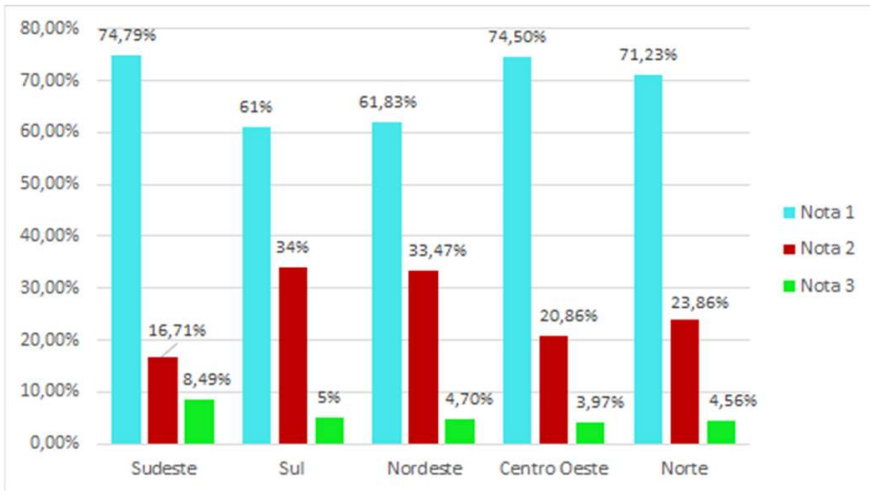

Gráfico 2: Avaliação da linearidade na formação do docente por área de conhecimento.

Fonte: Plataforma Lattes/CNPq (2020).

\section{Análise comparativa dos egressos nas regiões brasileiras}

O levantamento de dados sobre os egressos dos cursos de pós-graduação stricto sensu na área de Ciências Ambientais foi realizado por amostragem, segundo critérios explicados na seção metodológica. A tabela 6 apresenta a quantidade de cursos selecionados para compor as amostras por região e a tabela 7 apresenta a quantidade de egressos encontrados no âmbito da pesquisa.

Tabela 6: Quantidade de cursos das amostras selecionadas por região

\begin{tabular}{cc}
\hline Região & Quantidade de cursos \\
\hline Sudeste & 21 \\
Sul & 13 \\
Nordeste & 14 \\
Centro Oeste & 14 \\
Norte & 10 \\
\hline
\end{tabular}

Fonte: Plataforma Lattes/CNPq (2020)

Tabela 7: Quantidade de egressos por região para os anos de 2011 e 2019.

\begin{tabular}{cc}
\hline Região & Quantidade de egressos \\
\hline Sudeste & 341 \\
Sul & 219 \\
Nordeste & 369 \\
Centro Oeste & 181 \\
Norte & 93 \\
\hline
\end{tabular}

Fonte: Plataforma Lattes/CNPq (2020)

Em relação aos tipos de graduação dos egressos quantificados em cada região, tem-se as seguintes informações: na região Sudeste foram identificados 37 tipos de graduações diferentes, na região Sul 51 tipos de graduações diferentes, na região Nordeste 61 tipos de graduações diferentes, na Região Centro Oeste 48 tipos de graduações diferentes e na região Norte 29 tipos de graduação diferentes. Os cinco tipos de graduação predominantes por região estão apresentados no gráfico 3 . 


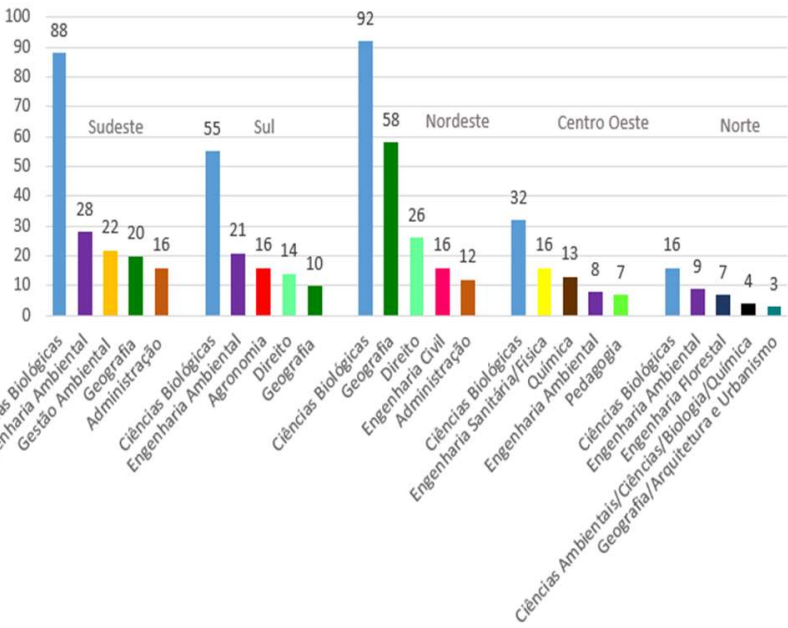

Gráfico 3: Cinco tipos de graduações predominantes em relação aos egressos levantados. Fonte: Plataforma Lattes/CNPq (2020).

Considerando a formação em nível de graduação dos egressos, é importante ressaltar que as áreas de conhecimento sobre a qual são classificadas possuem uma semelhança em comparação com a dos docentes, visto que a graduação em Ciências Biológicas apareceu em primeiro lugar em todas as regiões. Houve também uma semelhança para o segundo lugar entre as regiões Sudeste, Sul e Norte, com a formação em Engenharia Ambiental. Diante disso, afirma-se que as áreas de conhecimento em que estão inseridas as principais graduações dos egressos são: Ciências Biológicas, Engenharias, Ciências Humanas, Ciências Agrárias, Ciências Exatas e da Terra e Ciências Sociais Aplicadas, nessa ordem.

Evidencia-se pela diversidade de áreas de conhecimento abrangendo a formação dos egressos uma possibilidade de intercâmbio entre saberes com o docente, favorecendo a prática da interdisciplinaridade na elaboração de pesquisas. A cooperação mútua entre as diferentes áreas contribui de forma relevante para o enriquecimento de métodos, conceitos e técnicas a serem utilizadas para inovação e a busca por novas aplicações. A interdisciplinaridade ambiental convida os diversos especialistas à participação, pois ao estar diante de um mesmo objeto de estudo cada pesquisador possui visões e concepções diferentes sobre o mesmo, buscando aplicações de diferentes métodos e abordagens para a solução, o que implica na integração de saberes, conforme os preceitos de Leff (2000, 2001 e 2002).

Em relação à quantidade de egressos que possuem duas ou mais graduações, têm-se as seguintes porcentagens, de acordo com as regiões, sendo elas: região Sudeste 60 alunos, representando 17,6\% do total de egressos da amostra; região Sul apenas 4 alunos, representando 1,8\% do total de egressos da amostra; região Nordeste 29 alunos, representando $7,86 \%$ do total de egressos da amostra; na região Centro Oeste 11 alunos, representando 6,8\% do total da amostra e na região Norte 3 alunos, representando $3,37 \%$ da amostra.

Para a etapa da coleta de dados sobre os egressos, algumas dificuldades relevantes foram encontradas, dentre elas, o currículo desatualizado, a inexistência do currículo e a estrutura da página eletrônica dos programas, no sentido de facilitar o acesso às informações. Desse modo, não foi possível encontrar o currículo de alguns egressos. A respeito da quantidade de dissertações ou teses defendidas nos anos de 2011 e de 2019, os dados são expostos na tabela 8, para cada região. 
Tabela 8: Quantidade de dissertações e teses defendidas nos anos de 2011 e de 2019, por região

\begin{tabular}{ccccc}
\hline Região & Dissertações defendidas & Dissertações defendidas & Teses defendidas & Teses defendidas \\
& 2011 & 2019 & 2011 & 2019 \\
\hline Sudeste & 40 & 262 & 17 & 22 \\
Sul & 91 & 109 & - & 19 \\
Nordeste & 146 & 186 & 15 & 22 \\
Centro Oeste & 102 & 48 & 12 & 19 \\
Norte & 18 & 62 & 4 & 9 \\
\hline
\end{tabular}

Fonte: Páginas eletrônicas dos programas de pós-graduação (2020).

Quanto aos dados sobre a quantidade de dissertações e teses defendidas, em comparação entre os anos de 2011 e de 2019, observa-se um aumento expressivo em todas as regiões, exceto na região Centro Oeste, evidenciando que existe um crescente interesse de profissionais pela área, e também das pesquisas envolvendo as questões ambientais e de caráter interdisciplinar. No caso específico da região Centro Oeste, uma hipótese para explicar a diminuição dos trabalhos defendidos seria o aumento da oferta de cursos de pós-graduação disciplinares nessa região ou a diminuição do fluxo migratório de estudantes que, antes, saíam de outras regiões, como a região Norte, para estudar no Centro Oeste. Em outras palavras, a abertura de cursos em uma região pode contribuir para diminuir a busca por cursos de pós-graduação em outra, ainda que tal situação necessite de maiores investigações e esclarecimentos. Ao analisar a linearidade entre as formações dos egressos e docentes (orientadores), os resultados são apresentados no gráfico 4.

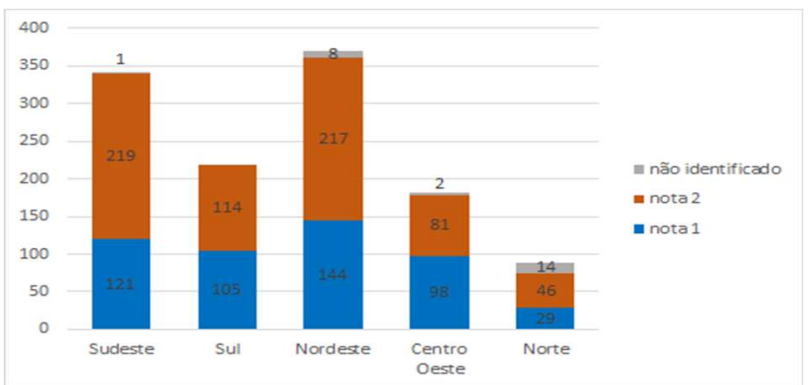

Gráfico 4: Linearidade entre as formações dos egressos e docentes. Fonte: Plataforma Lattes/CNPq (2020).

Quanto aos classificados com a nota 2, ou seja, aqueles casos em que o egresso e o docente possuem a graduação em áreas de conhecimento distintas, verificam-se números maiores, além de relativamente semelhantes em todas as regiões, com exceção da região Centro Oeste, onde a linearidade (formação na mesma área de conhecimento para orientador e orientando, indicada com a nota 1) mostrouse maior. Os resultados indicam que, de modo geral, há certa tendência ao diálogo entre as diferentes áreas na elaboração de trabalhos acadêmicos na área de Ciências Ambientais.

A interdisciplinaridade surge como um caminho a ser desenvolvido diante da complexidade dos problemas ambientais, sobre os quais os conhecimentos disciplinares, utilizados anteriormente, não alcançam um entendimento completo sobre suas causas, efeitos e soluções. Diante disso, a junção dos diversos métodos e práticas disciplinares, associados a suas visões, conhecimentos e habilidades, podem articular-se na busca por soluções dos problemas ambientais, proporcionando um diálogo entre saberes. Desse diálogo resultam novas práticas, superando gradativamente a fragmentação do conhecimento rumo a uma visão de conjunto, em uma retroalimentação positiva. 


\section{CONCLUSÕES}

A interdisciplinaridade se apresenta como uma prática em construção, visto que possibilita a aproximação de campos disciplinares diferentes em busca de soluções para problemas advindos da complexa relação entre sociedade e natureza. Existe, nessa seara, uma enorme demanda por compartilhamento de metodologias e por migração de conceitos, empreitada assumida pela área de Ciências Ambientais da CAPES, por meio dos programas de pós-graduação a ela vinculados. Por sua vez, os programas de pós-graduação são formados por seu corpo docente e discente, sujeitos em interação e que constituíram o foco deste trabalho, além de responsáveis pelos processos e produtos de pesquisa.

Os principais resultados mostraram certo grau de semelhança entre as regiões brasileiras no que diz respeito à formação dos docentes, com predominância das Ciências Biológicas, e uma trajetória mais disciplinar nos três níveis formativos (graduação, mestrado e doutorado). Os egressos, por sua vez, também apresentaram predominância nas Ciências Biológicas, embora com maior diversidade de formações em nível de graduação, bem como um caráter interdisciplinar mais evidente em relação à formação de seus orientadores (formação orientador/orientando). De um modo amplo, a identificação das formações, tanto dos docentes quanto dos egressos, permitiu encontrar uma ampla variedade de cursos e áreas de conhecimento, o que possibilita o enriquecimento e a complementaridade na construção de concepções coletivas.

Percebe-se uma mudança de perfil entre docentes e egressos, por meio do levantamento realizado: uma nova geração de pesquisadores com perfil mais interdisciplinar que a geração precedente. Entre outras implicações, isso indica uma tendência ao desenvolvimento do diálogo e à superação gradual das barreiras entre as disciplinas, sendo favorável à prática da interdisciplinaridade.

Como afirmam Jantsch et al. (1995), a interdisciplinaridade se trata antes de um processo ou exercício, portanto em construção e movimento, o que significa não estar orientada por uma epistemologia consolidada e um método estabelecido, com contornos bem definidos. Logo, o trabalho não teve a pretensão de rotular a interdisciplinaridade, mesmo porque não foram avaliados os conteúdos das produções acadêmicas. Foram observadas as formações como uma possibilidade preliminar para o exercício interdisciplinar, ou seja, a diversidade de formações foi aqui compreendida tão somente como uma condição inicial para o exercício da prática interdisciplinar.

A atitude interdisciplinar exige do pesquisador algumas mudanças de postura no âmbito da pesquisa, tais como: estar aberto ao diálogo e ao aprendizado constante ou aprender com os erros; ao invés de competição, adotar a cooperação; compreender o seu papel no processo e a depender do objeto de estudo ser mais ou menos exigido, não havendo lugar para vaidades individuais; respeitar as diferenças, o que traz a valorização da ética interpessoal; e aceitar opiniões que às vezes fogem ao seu campo de certeza disciplinar. É ainda necessário que a universidade possibilite a construção de pontes para a realização de diálogos em sua estrutura institucional, buscando valorizar o envolvimento coletivo, a criação de grupo de estudos interdisciplinares, a inclusão de coorientadores (com formações distintas) nas pesquisas, a criação de disciplinas ministradas por diferentes docentes e a contemplação de perfis 
interdisciplinares de formação no escopo dos editais de seus concursos públicos.

Por fim, as dificuldades encontradas no decorrer da pesquisa foram: inconsistências das informações nas páginas eletrônicas dos programas de pós-graduação, inconsistências nos currículos e até a não localização de currículos, tanto de docentes quanto de egressos. No sentido de aprofundamento da investigação, seria necessária a análise detalhada do conteúdo dos trabalhos produzidos (dissertações e teses), a fim de avaliar a interdisciplinaridade nos textos. Por ora, espera-se ter trazido alguma contribuição ao debate por meio do panorama traçado neste artigo.

\section{REFERÊNCIAS}

ASSIS, L. F. S.. Interdisciplinaridade: necessidade das ciências modernas e imperativo das questões ambientais. In: PHILLIPI JUNIOR, A.; TUCCI, C. E. M.; HOGAN, D. J.; NAVEGANTES, R.. Interdisciplinaridade em Ciências Ambientais. São Paulo: Signus Editora, 2000.

BARRETO, A. L.; FILGUEIRAS, C. A. L.. Origens da universidade brasileira. Química Nova, v.30, n.7, p.1780-1790, 2007.

BAUMGARTEN, M.; TEIXEIRA, A. N.; LIMA, G.. Sociedade e conhecimento: novas tecnologias e desafios para a produção de conhecimento nas Ciências Sociais. Sociedade e Estado, v.22, n.2, p.401-33, 2007.

BOWLER, P. J.. The Norton history of the environmental sciences. New York: W.W. Norton \& Company, 1992.

CAPES. Coordenação de Aperfeiçoamento de Pessoal de Nível Superior. Documento de área 2013 - Ciências Ambientais. 2013.

CAPES. Coordenação de Aperfeiçoamento de Pessoal de Nível Superior. Documento de área 2016 - Ciências Ambientais. 2016.

CESCO, S.. Interdisciplinaridade e temas socioambientais. Estudos Avançados, v.25, n.72, p.327-330, 2011.

COIMBRA, J. A. A.. Considerações sobre a interdisciplinaridade. In: PHILLIPI JUNIOR, A.; TUCCI, C. E. M.; HOGAN, D. J.; NAVEGANTES, R.. Interdisciplinaridade em Ciências Ambientais. São Paulo: Signus Editora, p.52-70, 2000.

ETGES, N. J.. Produção do conhecimento e interdisciplinaridade. Educação e Realidade, v.18, n.2, p.7382, 1993.

FAZENDA, I. C. A.. Interdisciplinaridade: história, teoria e pesquisa. 11 ed. Campinas: Papirus, 2003.

JANTSCH, A. P.; BIANCHETTI, L.. Universidade e interdisciplinaridade. In: JANTSCH, A. P.; BIANCHETTI, L.. Interdisciplinaridade: para além da filosofia do sujeito. Petrópolis: Vozes, 1995, p.195-204.
LEFF, E.. Complexidade, Interdisciplinaridade e Saber Ambiental. In: PHILLIPI JUNIOR, A.; TUCCI, C. E. M.; HOGAN, D. J.; NAVEGANTES, R.. Interdisciplinaridade em Ciências Ambientais. São Paulo: Signus Editora, 2000, p.19-51.

LEFT, E.. Saber ambiental: sustentabilidade, racionalidade, complexidade, poder. 3 ed. Petrópolis: Vozes, 2001.

LEFT, E.. Epistemologia ambiental. 3 ed. São Paulo: Cortez, 2002.

LENOIR, Y.; HASNI, A.. La interdisciplinaridad: por un matrimonio abierto de la razón, de la mano y del corazón. Revista Iberoamericana de Educación, n.35, p.167-185, 2004.

MARANHÃO, T. P. A.. Produção Interdisciplinar de conhecimento científico: temas ambientais. Sociedade e Estado, v.25, n.3, p.561-580, 2010.

MORIN, E.. Os sete saberes necessários à educação do futuro. 2 ed. São Paulo: Cortez, 2000.

PETRAGLIA, I. C.. Edgar Morin: a educação e a complexidade do ser e do saber. 9 ed. Petrópolis: Vozes, 1995.

PHILIPPI JUNIOR, A.; SOBRAL, M. C.; FERNANDES, V.; SAMPAIO, C. A. C.. Desenvolvimento sustentável, interdisciplinaridade e Ciências Ambientais. Revista Brasileira de Pós-Graduação, v.10, n.21, p.509-533, 2013.

PHILLIPI JUNIOR, A.; TUCCI, C. E. M.; HOGAN, D. J.; NAVEGANTES, R.. Interdisciplinaridade em Ciências Ambientais. São Paulo: Signus Editora, 2000.

SATOLO, V. P. X.; BERNARdO, C. H. C.; LOURENZANI, A. E. B. S.; MORALES, A. G.. Um Panorama Histórico-conceitual da Pesquisa Interdisciplinar: uma análise a partir da pósgraduação da área interdisciplinar. Educação em Revista, v.35, p.1-25, 2019

ZABALZA, M. A.. O ensino universitário: seu cenário e seus protagonistas. Porto Alegre: Artmed, 2004.

A CBPC - Companhia Brasileira de Produção Científica (CNPJ: 11.221.422/0001-03) detém os direitos materiais desta publicação. Os direitos referem-se à publicação do trabalho em qualquer parte do mundo, incluindo os direitos às renovações, expansões e disseminações da contribuição, bem como outros direitos subsidiários. Todos os trabalhos publicados eletronicamente poderão posteriormente ser publicados em coletâneas impressas sob coordenação da Sustenere Publishing, da Companhia Brasileira de Produção Científica e seus parceiros autorizados. Os (as) autores (as) preservam os direitos autorais, mas não têm permissão para a publicação da contribuição em outro meio, impresso ou digital, em português ou em tradução. 